\title{
PILATOS, DE CARLOS HEITOR CONY: MA ESCRITA DE RESISTÊNCIA
}

\author{
Camila Marcelina Pasqual ${ }^{1}$
}

RESUMO: Este artigo se propõe examinar estratégicas de escrita de resistência, adotadas na fiç̧ão de Carlos Heitor Cony. Autor engajado na luta revolucionária, confrontou o regime civil-militar em suas crônicas e em alguns romances, com isso conquistou o seu espaço junto ao meio intelectual da época. Selecionei como objeto de estudo, o romance Pilatos publicado em 1974, por se tratar e uma narrativa de temática e de estilo de escrita beirando ao insólito, ao grotesco e ao escatológico. Cony, por meio desse exercício de escrita, critica o autoritarismo e a falta de liberdade de expressão do período mais agudo da ditadura militar brasileira: os chamados "Anos de Chumbo". O autor transfere para o campo literário a noção de liberdade de expressão na voz narrativa do seu mutilado protagonista. O narrador é um indivíduo frustrado, solitário e melancólico, mas que está em busca de um forte anseio por liberdade.

Palavras-chave: liberdade; autoritarismo; resistência; Carlos Heitor Cony.

\section{PILATOS, BY CARLOS HEITOR CONY: A WRITING OF RESISTANCE}

ABSTRACT: This article proposes examine the strategy of resistant writing adopted in the fiction by Carlos Heitor Cony. An author engaged in the revolutionary fight, who confronted the civil-military regime in his chronicles and some novels and with this conquered his space together with the intellectual group of that era. I chose as object of this study, the novel Pilatos published in 1974. Due to being a thematic narrative, verging on an unusual, grotesque and eschatological. Cony by means of this exercise of writing criticizes the authoritarianism and lack of freedom of speech, in the most poignant time of the civil-military dictatorship in Brazil, the so-called: "Anos de Chumbo". The author transfers to the literary field the notion of freedom of expression in the narrative voice of his mutilated protagonist. The narrator is a frustrated individual, solitary and melancholic, but is in search of a yearning for freedom.

Key words: Freedom; authoritarianism; resistance; Carlos Heitor Cony.

1 Professora titular da Faculdade Educacional da Lapa (FAEL) e professora da SEED do Estado do Paraná. E-mail: camilapasqual11@hotmail.com 
O presente artigo tem por finalidade examinar estratégicas de escrita de resistência na obra ficcional de Carlos Heitor Cony. Ao lado de Antônio Callado, Cony foi um símbolo da resistência e, como jornalista e escritor, sempre se posicionou contra o autoritarismo imposto pelo governo no período da Ditadura militar no Brasil (1964-1985).

Publicado originalmente em 1974, Pilatos apresenta características de uma escrita inovadora. Nesse texto, a inovação se situa em um estilo de linguagem insólita, grotesca e escatológica, e traz como temática uma sarcástica crítica aos "Anos de Chumbo", a qual entra em primeiro plano no romance Pilatos. Dessa forma, Cony rompe com a expectativa de público e de crítica a abandonar a vertente de crítica política explícita do romance Pessach: a travessia de 1967, sem, paradoxalmente, deixar de dialogar ou aderir ao discurso de resistência. Tem-se em vista que os tipos com os quais o narrador protagonista de Pilatos cruza são, em sua maioria, excluídos e marginalizados da sociedade, vítimas da violência policial e de uma estrutura social opressora.

A escolha pela referida obra justifica-se pela escrita de estilo insólito, grotesco e escatológico e por apresentar uma narrativa vista sob a ótica da classe marginalizada que busca se libertar das amarras das pressões políticas "castradoras", à procura de um forte desejo de liberdade de expressão.

Partimos da hipótese de que Cony, por meio da voz narradora de Pilatos, expressa sua frustração, raiva e desilusão, com a situação política repressora e violenta, e ao mesmo tempo manifesta sua indignação com a alienação de boa parte da intelectualidade brasileira diante da consolidação do regime autoritário e ilegítimo do governo ditatorial brasileiro.

Pilatos foi o último romance de Cony dessa primeira fase intensa de produção, o qual viria marcar a despedida definitiva da carreira ficcional literária do autor. O título do livro foi extraído de uma composição popular, "Samba Erudito", de Paulo Vanzolini, e na epígrafe do romance, traz um fragmento da letra do samba: "E assim me rendi ante a força dos fatos:/ lavei as minhas mãos como Pôncio Pilatos." Após a publicação de Pilatos, Cony só retoma a escrita ficcional no ano de 1995 com a publicação de Quase Memória: Quase romance. Do ponto de vista estético, o autor nomeia o romance Pilatos como a sua melhor e mais autêntica produção literária e o único romance que só ele poderia ter escrito.

Segundo Cícero Sandroni (2003, p.117), Cony escreveu Pilatos com o intuito de descarregar um sentimento de desprezo e raiva "pela vida de escritor que foi se tornando cada vez maior" diante dos fatos sociopolíticos arbitrários que ele vinha enfrentando desde a eclosão do regime militar em 1964. Daí a justificativa do título do livro. Cony "desistiu” de lutar diante dos acontecimentos políticos dos anos 1970, uma vez que "não podia fazer mais nada contra a força dos fatos, a não ser lavar as mãos".

Sandroni (2003, p.118) assevera que, no protagonista de Pilatos, é difícil encontrar mãos lavadas, "mas a sujeira, o sofrimento, a miséria e a desgraça daqueles anos, diante dos quais quem narra, em vez de lavar as mãos, mete os dedos temperados com sal e vinagre nas mais dolorosas feridas, ainda hoje abertas, da sociedade brasileira".

Na contracapa do romance, Otto Maria Carpeaux (1974), um dos poucos amigos com o qual Cony teve intimidade profunda e profissional, alerta o leitor para lavar as mãos antes de pegar no "Pilatos" de Cony, e aponta que o humor abundante do livro está repleto de símbolos, ou então, é o "mesmo símbolo de uma tristeza desconsoladora". 
Carlos Heitor Cony, quando lançou Pilatos em 1974, havia sete anos que não publicava nenhum romance. A sua última obra, antes de Pilatos, foi Pessach: a travessia de 1967, romance lançado contra a vontade contestadora do regime militar. Escrito em primeira pessoa, o personagem Paulo Simões se envolve com militantes revolucionários dispostos a se arriscarem pela liberdade. O livro causara desconforto à esquerda ligada ao Partido Comunista que considerava agressivos e afrontosos os trechos em que militantes da luta armada demonstravam suas fraquezas e vilanias. Paulo Francis (1997), na orelha da quinta edição de Pessach: a travessia, aponta que Cony usou "o Ethos da esquerda como metáfora do subdesenvolvimento, da nossa sufocante insatisfação cultural, que se estende à individualidade de cada um". Todavia, a escrita de resistência do escritor é anterior ao Pessach: a travessia.

Eurídice Figueiredo (2017 p. 49) ressalta que, com a eclosão do golpe militar em 1964, em suas crônicas, "reunidas em livro já em 1964 com o título de O ato e o fato, ele [i.e., Cony] comenta que tais crônicas provocaram a cólera dos militares ao criticar a quartelada em suas crônicas publicadas", no único jornal defensor da democracia: Correio da Manhã. Por meio desse jornal é que Cony enfrentou de maneira isolada a tensão do regime militar na época.

Vale destacar que o termo tensão, aqui, não é acidental. Na acepção concedida ao vocábulo “tensão", Alfredo Bosi (2002, p. 130) afirma que o conceito está implícito na própria "ideia de resistência". Daí que, nas chamadas "narrativas de resistência", dá-se o momento "em que a tensão eu/mundo se exprime mediante uma perspectiva crítica, imanente à escrita, o que torna o romance não mais uma variante literária da rotina social, mas o seu avesso; logo, o oposto do discurso ideológico do homem médio” (BOSI, 2002, p. 130).

Cony traz em Pilatos, por intermédio da voz do narrador, um homem com pênis decepado, uma crítica sarcástica que aponta para a castração da liberdade de expressão, principalmente no meio intelectual. Além da castração da liberdade, o autor também se valeu da metáfora da castração em sua escrita para resistir às formas de opressão e confundir os censores da época, para que sua produção ficcional conseguisse passar pelo crivo dos censores. Dessa forma, o autor cria um narrador, segundo o seu desejo, ao lançar mão de uma escrita insólita em estilo grotesco e escatológico para fortalecer as possibilidades de exposição do "eu narrativo".

Para Alfredo Bosi (2002, p. 125), resistência é uma força que resiste a outra, exterior ao sujeito, que quando conjugadas à narrativa se realizam de duas maneiras distintas: "resistência como tema da narrativa e resistência como processo constitutivo de uma certa escrita".

A escrita resistente é a que empresta sua voz no sentido de resgatar o que foi dito no passado distante e que, frequentemente, foi ouvido por mais de uma testemunha. O crítico salienta ainda que "os valores mais autênticos e mais sofridos" são os que abrem caminho para emergir "à superfície do texto ficcional” (BOSI, 2002, p. 135).

É oportuno destacar que a literatura, assim como a música, a poesia, o teatro e demais manifestações culturais e artísticas, também necessitou se ajustar ao novo contexto de repressão e controle exercido pelo regime civil-militar. Acerca dos temas explorados pelos escritores, Regina Dalcastagnè (2007, p. 56) assevera "que a censura à produção ficcional foi menos intensa do que aquela dirigida à música e ao teatro, por isso, nossos autores se encon- 
traram na obrigação de abrir espaço em seus textos para a denúncia das arbitrariedades e dos crimes do regime". Para continuar exercendo sua atuação no campo ficcional literário, Cony se apropriou, em Pilatos, de uma escrita insólita, chocante e obscena que deveria estar fora de cena para os parâmetros morais, políticos e éticos da época. "É difícil - ou inútil - dar o início desta história. [...] Sei que a história existe, está escrita e inscrita em minha carne, mas creio que ela não teve início" (CONY, 2009, p. 11).

A obra é dividida em vinte e oito capítulos e separada em três partes, a narrativa de Pilatos é conduzida pela voz do narrador protagonista, Álvaro Picadura, que passa por uma série de amarguras e desilusões na vida. O enredo é ambientado no Rio de Janeiro da década de 1970, período de intensa repressão do regime ditatorial. O narrador, Álvaro, sofreu um acidente automobilístico e ao acordar na cama de um hospital filantrópico percebe que teve seu pênis amputado e na mesa de cabeceira, vê um vidro de compota com o seu "Herodes", e após dois meses de internação deixa o hospital, levando consigo seu pênis mutilado. $\mathrm{O}$ acidente e o período em que ficou internado lhe custaram o emprego, e também fora despejado da pensão onde morava por falta de pagamento. Após a sua saída do hospital, a castração lhe desperta um gradativo sentimento de vazio, melancolia e solidão que o persegue por toda a narrativa.

Álvaro, desempregado e fraco, com pouco dinheiro, vaga sem propósito pelas ruas do Rio de Janeiro. O pouco dinheiro que ainda lhe restava, acabou. Obrigado a procurar emprego, porém, com sua condição física debilitada, seu estado emocional abalado e sua aparência de mendigo, acreditava que suas chances de conseguir um trabalho seriam bastante restritas. Essa condição o levou a pensar que, talvez, com o seu pênis decepado guardado no vidro de composta que carregava, pudesse ganhar algum dinheiro. A partir de então, o pênis começa a ser utilizado como forma de ganhar dinheiro.

A imagem de Álvaro e seu pênis mutilado, na visão de Sandroni (2003, p. 26) "induz a ideia da própria castração do autor”, e de sua própria condição de intelectual durante o período mais repressivo da ditadura seria, portanto, o primeiro momento no enredo no qual o autor, por meio da escrita insólita e escatológica, explora a utilidade e o valor de sua criação literária. Eurídice Figueiredo (2017, p. 45) pontua que na ficção a estratégia ordenadora de linguagem é parte essencial do ato de narrar, "mas a fantasia só surge nas narrativas de valor testemunhal para exprimir as incongruências e as ironias do comportamento autoritário".

Bosi (2002) aponta para o espaço da literatura, considerado em geral como o lugar de fantasia, mas que pode ser o lugar da verdade mais exigente. "É nesse sentido que se pode dizer que a narrativa descobre a vida verdadeira, e que esta abraça e transcende a vida real" (BOSI, 2002, p. 135). Dessa forma, a narrativa de Pilatos exerce a função de informar por meio da "fantasia" a realidade do contexto ditatorial, e é através da ironia cáustica e da linguagem grotesca e obscena que a obra ganha tom de resistência.

O narrador ao sair do hospital, sem emprego, sem lugar para dormir e quase sem dinheiro, após vagar sem rumo pelas ruas do Rio de Janeiro, encontra uma hospedaria simples a qual teria condições de pagar por uma noite de sono, mas o alojamento do seu Fernandes era sujo e se encontrava em péssimas condições de higiene, sequer possuía camas para dormir. A hospedaria parecia um presídio, em que os hóspedes eram autorizados a entrar às 20 horas e às 6 horas da manhã eram despejados do local aos chutes e pontapés. 
Assim relata Álvaro a respeito da sua primeira noite após deixar o hospital:

Repetindo o ritual que devia ser o mesmo de todas as noites, foi num dos cantos e apanhou uma corda suja e puída. Passou uma das pontas por uma argola sustentada num pedaço de ferro cravado no assoalho. Esticou a corda e passou a mesma ponta por outra argola em outro canto, e assim armou uma espécie de ringue em frente aos bancos. Ficava uns trinta centímetros de nossa cara e foi então que compreendi o seu funcionamento. Tão logo seu Fernandes amarrou a corda na última argola, todos se curvaram e nela apoiaram os braços e cabeça. No início, a coisa balançou muito, até que todos se ajeitassem. Logo se fixou: a maior parte começou a dormir. Os poucos que resistiam ao sono não se sentiam à vontade para mexer a cabeça. [...]. Em condições normais, jamais conseguiria dormir naquela posição. Mas sem pau e sem colhões eu ficava em estado de permanente anormalidade. Para ser exato: minha anormalidade começava a ser normal. E estava cansado. Caí numa sonolência que não era sono, mas parecia. (CONY, 2009, p. 42)

Na passagem transcrita acima, é possível perceber que o narrador castrado, sem teto, em situação de maltrapilho, agarrado ao seu pênis decepado mergulhado em um vidro de compota, sentiu-se obrigado a apoiar-se sobre uma corda para descansar. Tal situação seria semelhante à de Cony e à dos demais escritores militantes brasileiros, na década de 1970 . Sentindo-se obrigados a reinventarem estratégias de escrita para evitarem agressões políticas, assim como a vida do narrador tendo de se submeter a uma situação humilhante, a vida dos escritores brasileiros que viviam em constante insegurança sob rígida vigilância das arbitrariedades do governo militar não seria diferente.

Rodrigo Castro Orellana (2011-2012, p. 44), apoiado nas discussões de Michel Foucault, em $A$ vontade do saber, afirma que "os pontos de resistência têm seu ápice nos mecanismos de sujeição, reinventando-se a partir do enfrentamento, escrevendo sua diferença sob a linguagem do poder".

Uma das características mais marcantes do protagonista de Pilatos é o apego excessivo por seu pênis mutilado. Sendo assim, Álvaro faz um juramento de jamais se separar do seu pênis decepado, única razão da sua vida, embora o narrador não tivesse nenhuma razão para continuar vivendo. O "Herodes" "era mais do que uma relíquia ou um amuleto. Era também um fato histórico" que inauguraria um novo ciclo em sua vida. Nas palavras do narrador, o "Herodes" "era mais meu, agora, do que antes. Dependia de mim, eu o trataria como um pássaro - um pássaro ferido e importante, um pássaro do qual foram arrancados os olhos e as asas, mas que se obstinava em viver e ser meu. (CONY, 2009, p. 35-36)

É possível destacar que o pênis "Herodes" nos remete ao período intenso de repressão do regime ditatorial, quando os grupos de resistência estavam sendo derrotados pela violenta perseguição do governo. O pássaro ferido com as asas arrancadas e os olhos destroçados seria a metáfora da violência e da tortura sofrida pelos intelectuais, artistas e escritores que foram presos e na cela sofriam as mais variadas formas de tortura e violência.

O apego do protagonista ao seu pênis decepado pode ser interpretado também como o apelo de Cony como escritor de ficção literária. Apesar do tom melancólico na passagem 
supracitada, é possível observar que Cony mais uma vez deixa subentendida a sua determinação de continuar escrevendo na tentativa de assegurar a importância da sua produção literária. Nesse sentido, afirma Rodrigo Castro Orellana, (2011-2012, p. 59) o escritor que luta contra o intolerável, constitui uma "ferramenta decisiva de resistência para intervir no espaço desta secreta violência".

Ao final da primeira parte da trama, o protagonista encontra Joaquim dos Passos, personagem que vive em condições semelhantes, mas tem ideias excêntricas e absurdas. $\mathrm{O}$ encontro entre os dois é muito significativo, pois a relação entre eles vai perpassar toda a narrativa. A partir de então, os dois personagens se tornam amigos e companheiros inseparáveis. Os planos que Dos Passos vai elaborar para conseguir dinheiro à custa de "Herodes" será o tema central dessa segunda parte. Essa é a parte da narrativa em que podemos perceber a sátira e o humor debochado do escritor atingindo seu grau máximo de sarcasmo. Cony não poupa ninguém, nem mesmo os artistas e intelectuais da época.

O primeiro plano de Dos Passos, para ganhar dinheiro com o "Herodes" do amigo, fracassou. Dos Passos observa uma equipe de gravação de um filme cuja cena era o nascer do sol, mas com o atraso da equipe produtora, acabou resultando na perda do momento desejado para realizar as gravações. Houve, então, uma discussão entre o diretor e a produtora do filme. Ao ouvir o teor da conversa, Dos Passos teve uma ideia, a qual apresentou ao diretor e ao produtor do filme, e ambos gostaram da sugestão: a cena filmada com o nascer do sol seria substituída por outra, na qual ocorria a adoração do pênis amputado do seu amigo.

Assim afirma o narrador: "adoração ao sol, na realidade, seria uma cena simbólica, tudo era simbólico no filme, menos o Pedro Álvares Cabral, que ali estava, suando em suas barbas postiças e em suas roupas escamadas de pedrarias, parecendo ter saído de um baile de Carnaval" (CONY, 2009, p. 84).

Álvaro concordou com a ideia de Dos Passos e, em troca de um cachê de cem cruzeiros, acabou cedendo "Herodes" para a gravação, mesmo sem entender direito o roteiro do filme. Ao término das filmagens do "Herodes", Dos Passos e Álvaro receberam a "merecida paga: com um cheque sem fundos" (CONY, 2009, p. 84).

Considerando que no filme, "tudo era simbólico", pode ser tomada como uma crítica irônica de Cony a alguns artistas e intelectuais brasileiros que tentavam produzir uma "arte" que passasse pelo crivo da censura e, ao mesmo tempo, fizesse críticas ao governo militar, porém acabavam produzindo uma arte sem fundamento e extravagante. Segundo Homero Vizeu Araújo (2004, p. 150), “o roteiro do filme para o qual Álvaro cedeu "Herodes" para uma participação especial seria uma sátira de Cony aos desvairados roteiros dos filmes de Glauber Rocha”.

$\mathrm{Na}$ passagem do "violino afrodisíaco", levado pelas ideias pervertidas e sonhadoras do amigo fascista, o narrador arranca os próprios pelos pubianos para que Dos Passos pudesse inventar uma "música luxuriosa", ao substituir as cordas originais de um violino pelos "pentelhos" do protagonista. Após testar os efeitos do violino em uma igreja durante a missa, Álvaro e Dos Passos seguiram rumo à festa de casamento na qual foram contratados para tocar violino naquela mesma noite. A melodia do bizarro instrumento musical passa a despertar um desenfreado apetite sexual nos convidados: 
Dos Passos entrou em transe. Do violino saía um som hediondo, a depravação era geral. Agora, todos estavam no chão, pelas cadeiras, em cima da mesa, até mesmo em cima de um armário. Excitado como um demônio diante de um querubim pervertido, Dos Passos passou-me o violino:- Toque esta joça que eu vou ali. O "ali" de Dos Passos era justamente em cima da mulata do dono da casa. E eu tomei o seu lugar na orquestra, o que foi minha danação. Não tinha habilidade para arrancar dos pentelhos aquele som fanhoso, acabei arrebentando-os, um a um. Justo no instante em que meia dúzia de policiais entraram na sala e prenderam todo mundo, principalmente, a mim, tomando-me como culpado de tudo. (CONY, 2009, p. 119)

Álvaro e Dos Passos foram presos pela polícia em função da noite de orgia na festa de casamento, estimulada pelo violino improvisado, por intermédio da voz narradora do protagonista, o autor revela o autoritarismo das cadeias da época e, a partir do discurso fascista de Dos Passos, a lógica do regime opressor tinha por objetivo combater o comunismo.

No fragmento transcrito acima, além de nos remeter ao regime opressor, nota-se que o sexo ocupa papel central, sendo explorado, de forma degradante, por meio da sátira e do deboche. Malcom Silverman (2000, p.130) aponta o exagero do autor ao descrever as relações sexuais de seus personagens:

Pela sua própria natureza, o homem se encontra psicologicamente dividido entre o desejo de tornar-se independente e a necessidade de conformar-se às restrições sociais. É um panorama fatalista, degradante e irônico do nosso lado negro, onde prevalece a insensibilidade. Aqui, o sexo ganha do amor; a hipocrisia, da sinceridade; a emoção, da razão; e a mente humana permanece num estado continuado de deterioração. O pequeno humor que existe tende a ser cáustico, isto é, cínico, sarcástico, mórbido e satírico. (SILVERMAN, 2000, p.130)

O narrador faz questão de relatar que nunca havia sido preso e se surpreende ao ver a prisão superlotada, ele "sempre imaginara que as celas eram desertas, silenciosas e frias".

Descemos do carro sob porrada e fomos jogados numa cela sem janelas, onde havia três colchões, uma lata que servia de latrina e, na parede mais larga, um gigantesco caralho pintado a carvão. Durante o trajeto, principalmente nas curvas, fôramos jogados uns contra os outros. Carnes e ossos que não haviam sido moídos durante a viagem, o foram na hora da descida, quando os policiais nos bateram com vontade e prazer. Tão logo nos vimos numa cela mais ou menos grande, ocupada apenas por nós cinco, parecia que chegáramos a uma espécie de paraíso. Em comparação com o cárcere da delegacia, equivalia a uma suíte de hotel. Caímos onde havia espaço e dormimos um pouco. E mais não dormimos porque a porta se abriu e um guarda jogou um balde de água em nossa cara. [...] O guarda fizera aquilo porque, segundo os regulamentos, nós devíamos tomar um banho - e o banho nos fora dado. (CONY, 2009, p. 123) 
$\mathrm{Na}$ passagem transcrita acima, o autor, mais uma vez, faz uma descrição realista e crua, em tom cínico e sarcástico a respeito do sistema prisional brasileiro. A superlotação das celas, as precárias condições de higiene, a promiscuidade, a acomodação e as prisões arbitrárias aparecem em vários episódios cômicos na narrativa em pauta. É importante ressaltar que essa escrita irônica, debochada e sarcástica faz alusão ao absurdo sistema prisional brasileiro e às cassações políticas da época.

Malcolm Silverman (2000, p. 130) observa que é exatamente essa "visão desmoralizante o elemento a ser supervalorizado - em associação à ironia, ao cinismo e ao sarcasmo" que o autor busca revelar, ao leitor, o que "há de mais irracional na razão da ordem estabelecida".

A libertação de Álvaro e de seus demais companheiros de cela acontece na última página da segunda parte do romance. Assim como foram presos sem nenhum motivo, a liberdade também veio de forma inesperada e sem avisos, deixando um novo ar de incerteza e insatisfação, como evidencia o narrador:

Aos poucos, compreendemos que era a liberdade, mas nem por isso ficamos satisfeitos. Nenhum de nós - creio - havia feito planos para a liberdade. E ela caiu sobre nossa cabeça como um desamparo, uma espécie de desemprego. Nem Dos Passos, nem o Grande Arquimandrita, dotados de imaginação, haviam previsto aquela hipótese. Nada se programara para a ocasião. Habituáramos à cela, às pancadas, à comida detestável. Assim como eu me conformara a viver sem pau, conformara-me a viver sem liberdade. (CONY, 2009, p.170; grifos meus)

O sentimento de melancolia, frustração e solidão acompanharam o protagonista até o dia em que foi preso, novamente esse sentimento se faz presente no dia de sua libertação, já que ele não tinha noção nem planos do que fazer com essa liberdade. O medo de Álvaro pela liberdade era a incerteza de conseguir emprego e obter recursos para sua sobrevivência: "Eu sabia o que a liberdade iria representar a curto prazo: fome. Tratei de comer o que podia, no que fui imitado [pelo companheiro de cela] o velho Sic Transit, que não precisava de nenhuma consideração especial para devorar tudo" (CONY, 2009, p. 170).

A prisão trazia incômodos e desconfortos; porém, para quem estava sem esperanças e sem perspectivas, como é o caso do narrador, a prisão seria a segurança, a estabilidade e a garantia de sua sobrevivência.

A liberdade e a insegurança que amedrontam o narrador fazem alusão à liberdade intelectual durante os "Anos de Chumbo", que, possivelmente, resultaria em privações e dificuldades financeiras para muitos presos políticos, como escritores, artistas, compositores, entre outros. Nesse contexto, Cony comenta a respeito dessa experiência, pela entrevista concedida ao jornalista André Luiz Barros, da revista Bravo!: "o lugar onde me senti mais livre na minha vida foi minha primeira noite na prisão. Sim, pela primeira vez eu estava no lugar certo na hora certa. Se eu estivesse em liberdade é que estava errado" (CONY apud SANDRONI, 2003, p. 97).

A última parte do livro é relativa à liberdade propriamente dita dos ex-presidiários, quais sejam: o narrador, Dos Passos, o Grande Arquimandrita, o Otávio e o velho Sic Transit. O grupo se manteve unido por mais duas noites. A partir de então, cada um tratou de 
seguir seu rumo na tentativa de conseguir algum emprego ou dinheiro. Álvaro arranjou um emprego de ajudante no bar de um português e, em troca, receberia comida e gorjetas. Devido à situação de pobreza em que se encontrava, ele aceitou, ao final do expediente, acabou deixando o vidro com "Herodes" na geladeira do estabelecimento e saiu à procura de um lugar para pernoitar.

Ao retornar ao bar, no dia seguinte, para o expediente normal, defrontou-se com o português saboreando seu pênis numa fritada que a cozinheira tinha preparado, achando que o órgão mutilado guardado no vidro de compota fosse, na verdade, uma linguiça. Diante da situação, o narrador a princípio ficou furioso, mas a raiva inicial passou, e constatou:

Herodes estava consumado. Não adiantava obrigar o sujeito a vomitar os pedaços do meu cacete. Uma pequena distração, uma só noite que ele passara distante dos meus cuidados, fora-lhe fatal. Acabara-se. Havia um pacto segundo o qual a minha vida só valeria a pena enquanto eu pudesse viver agarrado a ele. Agora não mais seria possível. Minha vida perdera sentido - coisa, de resto, que nunca teve. O pensamento não me deu alegria, mas me acalmou. (CONY, 2009, p. 198).

O dono do bar sugeriu que o "Herodes" fosse substituído por uma linguiça qualquer. A linguiça foi substituída, mais tarde, pelo pênis do personagem Sic Transit que acabou morrendo em consequência de um atropelamento. O novo pênis recebeu o apelido de "Herodes II". Sandroni (2003, p. 120) ressalta que o "Herodes" foi substituído por uma língua vulgar, "simbolizando sua renúncia a qualquer forma de poder, Álvaro Picadura joga-a na baía de Guanabara".

Pouco tempo depois da substituição do "Herodes" original pelo "Herodes II" falsificado, Dos Passos foi assassinado a tiros vindos de um carro enquanto perambulava pela rua em companhia de Álvaro. O protagonista foi levado à delegacia para prestar depoimento e foi informado de que o crime fora organizado por antigos parceiros de Dos Passos, que o consideravam perigoso e traidor. O narrador não acreditou nos falsos argumentos dados pela polícia, pois tinha certeza de que havia sido em razão de uma denúncia do ex-companheiro de cela, O Grande Arquimandrita que, após sair da cadeia, conseguiu um emprego no Departamento de Ordem Política e Social.

O narrador saiu da delegacia dolorido pela surra que levou e seguiu o seu caminho. Andando à beira da praia durante o resto da noite, cansado de sua triste jornada de atribulações, o narrador, sentado numa pedra admirando o horizonte, decide abandonar o "Herodes II", já era "madrugada, quando soprou a aragem do amanhecer, peguei o vidro e atirei-o ao mar”. (CONY, 2009, p. 222).

Ao lançar o "Herodes II" ao mar por considerá-lo "uma carga exagerada para carregar pela vida”, o narrador solitário, melancólico e mutilado afirma que a sua salvação deveria começar pela consciência, e, partir de então, começa a valorizar a própria vida, já que tudo lhe fora tirado: emprego, moradia, bens materiais e, principalmente, a sua virilidade.

A liberdade, após a saída da prisão, não representou o início de um novo ciclo de vida para o protagonista. Os sentimentos de melancolia, solidão e frustração que o acompanharam desde sua castração até sua prisão ainda estavam latentes em seu íntimo. O fato de ter 
conseguido um emprego em condições degradantes. Como a frustração, a solidão e a melancolia de Álvaro não se resumiam apenas à falta de dinheiro, passou então a refletir sobre sua nova condição de vida, e concluiu:

Minha vida resumia-se nos poucos milímetros quadrados da minha pele - mutilada pele, da qual um pedaço importante já fora arrancado, primeiramente do meu próprio corpo, depois de minha posse. [...] Aos poucos, nos conformávamos com uma vida menos miserável, mas lastimável, porque nos dava perspectiva para julgá-la. Cada vez que lavava as mãos pensava nisso. E me absolvia. Não era caso para cair em prantos. Tampouco para me encher de júbilo. Passara dias pensando em voltar às gráficas, à procura de um lugar de revisor de provas. (CONY, 2009, p. 204).

Ao fazer um balanço e analisando sua trajetória de vida até então, Álvaro Picadura revelou para si mesmo a realidade de um homem solitário, impotente e sem maiores ambições e perspectivas de vida. Impossibilitado de executar a sua função mais importante, o protagonista enverga-se à força dos fatos e lava as mãos, e alcança a "liberdade", ou melhor, uma liberdade aparente.

Os obstáculos e problemas enfrentados pelo protagonista de Pilatos podem ser resultantes das reflexões de Cony acerca de seu "inútil" trabalho como escritor, que decide encerrar definitivamente a sua produção literária após dez anos de vigência de ditadura civil-militar.

Pensando em termos de uma metáfora política, o sistema repressivo do governo ditatorial brasileiro nos vem primeiro à mente. Segundo Vizeu Araújo (2004, p. 154), "na castração do protagonista encontra-se sob a força do AI-5, a castração política do país?”. Em outros termos, a imagem da castração seria a representação de impotência, de desilusão e de angústia que tanto atormentou Cony e muitos outros intelectuais e escritores, especialmente aqueles que acreditavam no poder inovador da palavra escrita no período de maior violência e repressão do regime ditatorial no Brasil. O corajoso e engajado Cony de 1964 renuncia, ou melhor, abandona a produção literária ficcional, após a escrita de Pilatos. $\mathrm{O}$ autor, com esse romance, simboliza a sátira incisiva, grotesca e escatológica sobre a situação política e a contestação no Brasil durante os chamados "Anos de Chumbo", e lava as mãos.

\section{Referências Bibliográficas}

ARAÚJO, Homero José Vizeu. Pilatos: uma saga carioca mórbida e hilariante nos anos 70. Revista Letras, Curitiba, n. 64, p. 143-155. set./dez. 2004. Editora UFPR. Disponível em: <http://www.letras. ufpr.br/documentos/pdf revistas/araujo.pdf, acesso: 20 jul.2021.

BOSI, Alfredo. Narrativa de Resistência. In: BOSI, Alfredo. Literatura e resistência. São Paulo: Companhia das Letras, 2002.

CONY, Carlos Heitor Pessach: a travessia. São Paulo: Companhia das Letras, 1997. 
Pilatos. Rio de Janeiro: Objetiva, 2009.

. Contracapa de Pilatos, Rio de Janeiro: Civilização Brasileira, 1974

O ato e o fato: o som e a fúria do que se viu no Golpe de 1964. 9 ed. Rio de Janeiro:

Nova fronteira, 2014.

DALCASTAGNÉ, Regina. Nas tripas do cão: a escrita como espaço de resistência. Estudos de literatura brasileira contemporânea. Brasília, DF, n. 29, p. 55-66, jan./jun. 2007. Disponível em: https:// periodicos.unb.br/index.php/estudos/article/view/9117; acesso em: 27 Jun. 2021.

FIGUEIREDO, Eurídice. A literatura como arquivo da ditadura brasileira. Rio de Janeiro: 7 letras, 2017.

ORELlANA, Rodrigo de Castro. A ética da resistência. Ecopolítica. São Paulo, n.2, p. 37-63, 2011-2012. Disponível em:

https://revistas.pucsp.br/index.php/ecopolitica/article/view/9089; acesso em: 15 abr. 2021.

SANDRONI, Cícero. Quase Cony - Rio de Janeiro: Relume Dumará: Prefeitura, 2003.

SILVERMAN, Malcolm. Protesto e o novo romance brasileiro. 2a ed. Rio de Janeiro: Civilização Brasileira, 2000. 
